Article

\title{
High-Throughput Screening of Rare-Earth-Lean Intermetallic 1-13-X Compounds for Good Hard-Magnetic Properties
}

\author{
Georg Krugel ${ }^{1}$, Wolfgang Körner ${ }^{1, *}$, Daniel F. Urban ${ }^{1}$, Oliver Gutfleisch ${ }^{2,3}$ and \\ Christian Elsässer 1,4 \\ 1 Fraunhofer Institute for Mechanics of Materials IWM, Wöhlerstr. 11, 79108 Freiburg, Germany; \\ georg.krugel@ise.fraunhofer.de (G.K.); daniel.urban@iwm.fraunhofer.de (D.F.U.); \\ christian.elsaesser@iwm.fraunhofer.de (C.E.) \\ 2 Fraunhofer Project Group for Materials Recycling and Resource Strategy IWKS, Rodenbacher Chaussee 4, \\ 63457 Hanau, Germany; gutfleisch@fm.tu-darmstadt.de \\ 3 Technische Universität Darmstadt, Institute for Materials Science, Alarich-Weiss-Str. 16, \\ 64287 Darmstadt, Germany \\ 4 Freiburg Materials Research Center, University of Freiburg, Stefan-Meier-Str. 21, 79104 Freiburg , Germany \\ * Correspondence: wolfgang.koerner@iwm.fraunhofer.de
}

Received: 9 August 2019; Accepted: 2 October 2019; Published: 11 October 2019

\begin{abstract}
By computational high-throughput screening, the spontaneous magnetization $M_{s}$, uniaxial magnetocrystalline anisotropy constant $K_{1}$, anisotropy field $H_{a}$, and maximum energy product $(B H)_{\max }$ are estimated for ferromagnetic intermetallic phases with a tetragonal 1-13-X structure related to the $\mathrm{LaCo}_{9} \mathrm{Si}_{4}$ structure type. For $\mathrm{SmFe}_{13} \mathrm{~N}$, a $(B H)_{\max }$ as high as that of $\mathrm{Nd}_{2} \mathrm{Fe}_{14} \mathrm{~B}$ and a comparable $K_{1}$ are predicted. Further promising candidates of composition $\mathrm{SmFe}_{12} \mathrm{AN}$ with $\mathrm{A}=\mathrm{Co}, \mathrm{Ni}, \mathrm{Cu}, \mathrm{Zn}, \mathrm{Ga}, \mathrm{Ti}, \mathrm{V}$, $\mathrm{Al}$, Si, or $\mathrm{P}$ are identified which potentially reach $(\mathrm{BH})_{\max }$ values higher than $400 \mathrm{~kJ} / \mathrm{m}^{3}$ combined with significant $K_{1}$ values, while containing almost $50 \%$ less rare-earth atoms than $\mathrm{Nd}_{2} \mathrm{Fe}_{14} \mathrm{~B}$.
\end{abstract}

Keywords: uniaxial magnetocrystalline anisotropy; ferromagnetic intermetallic phases; computational high-throughput screening

\section{Introduction}

The environmentally friendly and resource-efficient exploitation of sustainable energy sources world-wide will further increase the demand for high-performance permanent magnets in electromagnetic energy-conversion machines like wind-turbine generators and electric-vehicle motors. Nowadays, $\mathrm{Nd}_{2} \mathrm{Fe}_{14} \mathrm{~B}$ alloyed with Dy is the best performing hard-magnetic material on the market for permanent magnets in these applications. However, this material can be used only in motors operating at moderate temperatures, and it suffers from the latent supply criticality of rare-earth elements, namely $\mathrm{Nd}$ and especially Dy, on the world market. As a consequence, intensive research activities in materials science and technology have been (re)started in recent years with the ambitious goal of discovering novel hard-magnetic materials and developing permanent magnets with comparable magnetic performance to $\mathrm{Nd}_{2} \mathrm{Fe}_{14} \mathrm{~B}$ but containing no or significantly less $\mathrm{Nd}$, Dy, or other supply-critical rare-earth elements [1-3]. One promising class of magnetic phases containing no rare-earth elements (RE) are the Heusler compounds [4]. Another RE-lean class is the one of intermetallic phases with a $\mathrm{NaZn}_{13}$-type crystal 
structure. These phases are potentially promising due to their favorable 1:13 ratio between rare earth elements and magnetic transition-metal elements (TM) like Fe or Co.

A hypothetical magnet made of $\mathrm{NdFe}_{13}$ has only about $50 \%$ of the $\mathrm{RE}$ content of a $\mathrm{Nd}_{2} \mathrm{Fe}_{14} \mathrm{~B}$ magnet. It is known that the intermetallic phase $\mathrm{LaCo}_{13}$, which has a structure of the $\mathrm{NaZn}_{13}$ type, can be stabilized by substituting Co with certain amounts of Fe and Si. Such compounds are highly interesting and investigated intensively in the context of exploiting the magnetocaloric effect for energy-efficient magnetic cooling [5-9].

Nevertheless, the intermetallic phases with $\mathrm{NaZn}_{13}$-type crystal structure (space group No. 226 $(F m \overline{3} \mathrm{c})$ ) are not immediately suitable for the application as hard magnets. Their cubic symmetry leads to a magnetocrystalline anisotropy energy (MAE) close to zero. One possibility to obtain a material with a reasonable anisotropy is to combine hard-magnetic $\mathrm{LaCo}_{5}$ with soft-magnetic $\mathrm{LaCo}_{13}$ in a two-phase microstructure [10].

The $\mathrm{LaCo}_{9} \mathrm{Si}_{4}$ structure [11,12], which is closely related to the cubic $\mathrm{NaZn}_{13}$ structure, has a tetragonal symmetry and therefore potentially an uniaxial and non-zero MAE. In this case, the tetragonality originates from the high fraction of $\mathrm{Si}$ atoms occupying the Wyckoff positions (161). Since the Si atoms are significantly smaller than the Co atoms (covalent radii are $R_{\mathrm{Si}}=111 \mathrm{pm}$ and $R_{\mathrm{Co}_{\mathrm{o}}}=126 \mathrm{pm}$ ), the crystal is tetragonally distorted. Unfortunately, such high amounts of $\mathrm{Si}$ in a Fe- or Co-rich phase deteriorate the magnetization massively and therefore prevent their usage in hard-magnetic applications.

In this paper, we take a different route to obtain a tetragonal distortion of the cubic $\mathrm{NaZn}_{13}$ structure. Our theoretical screening approach is addressing a modified variant of this 1-13 structure, denoted 1-13-X structure, which is obtained by introducing additional interstitial atoms on the Wyckoff positions (4c) of the $\mathrm{LaCo}_{9} \mathrm{Si}_{4}$ structure. Subsequently all structural parameters are relaxed by means of first-principles calculations based on density functional theory (DFT). The primary motivation for the alloying with light interstitial elements $\mathrm{X}=\mathrm{B}, \mathrm{C}$, or $\mathrm{N}$ is to enhance the tetragonal distortion of the $\mathrm{LaCo}_{9} \mathrm{Si}_{4}$ phase in order to increase the MAE. Moreover, as in the case of $\mathrm{NdFe}_{12} \mathrm{~N}$ and the related 1-12-X phases, the magnetocrystalline anisotropy may increase significantly as well when changing from the 1-13 to the $1-13-X$ phases by chemical bonding effects of the interstitial $X$ atoms [13-17].

The 1-13-X structure type (with $X=B, C$, or $N$ ) was screened theoretically in the way described in our previous work on the $\mathrm{ThMn}_{12}$-type and $\mathrm{YNi}_{9} \mathrm{In}_{2}$-type phases $[13,14]$. Hereby, we considered either $\mathrm{Nd}$ or Sm to sit on the RE site. The TM sites, originally occupied with Co or $\mathrm{Si}$ in $\mathrm{LaCo}_{9} \mathrm{Si}_{4}$, were decorated with magnetic transition-metal elements, namely $\mathrm{Mn}, \mathrm{Fe}, \mathrm{Co}$, and $\mathrm{Ni}$, and a variety of the non-magnetic elements $\mathrm{Al}, \mathrm{Si}, \mathrm{P}, \mathrm{Ti}, \mathrm{V}, \mathrm{Cr}, \mathrm{Cu}, \mathrm{Zn}, \mathrm{Ga}$, or $\mathrm{Sn}$. Altogether, 1250 compounds of the 1-13-X type were assessed.

In the following, the relationship of chemical compositions and intrinsic magnetic properties of the 1-13-X phases is investigated. As criteria for good permanent magnets we require a maximum energy product $(B H)_{\max } \geq 400 \mathrm{~kJ} / \mathrm{m}^{3}$ combined with an anisotropy constant $K_{1}$ of approximately $5 \mathrm{MJ} / \mathrm{m}^{3}$, which is comparable to that of $\mathrm{Nd}_{2} \mathrm{Fe}_{14} \mathrm{~B}$. Specifically $\mathrm{SmFe}{ }_{12} \mathrm{AN}$ with $\mathrm{A}=\mathrm{Fe}, \mathrm{Co}, \mathrm{Ni}, \mathrm{Cu}, \mathrm{Zn}, \mathrm{Ga}, \mathrm{Ti}, \mathrm{V}, \mathrm{Al}, \mathrm{Si}$, or $\mathrm{P}$ are proposed as RE-lean intermetallic RE-TM compounds with potentially good hard-magnetic properties.

\section{Theoretical Approach}

\subsection{Screening with TB-LMTO-ASA}

Our theoretical screening approach including the computation of the MAE within a DFT framework is based on the work of Fähnle and Hummler who developed an efficient evaluation of the crystal field parameters $A_{n m}$ with the tight-binding (TB) linear-muffin-tin-orbital (LMTO) [18] atomic-sphere approximation (ASA) method $[19,20]$. The TB-LMTO-ASA method has been demonstrated to work well for hard-magnetic RE-TM phases [13,19-21], since it treats the localized 'open-core' f-states in a physically 
proper and accurate manner by imposing a constraint on the occupation of the f-states in order to fulfill the conditions implied by Hund's rules [22].

The high-throughput-screening (HTS) setup by Drebov et al. [21] is used, which allows a fully automated generation of new phases by combinatorial substitution of sets of equivalent atoms combined with the subsequent DFT calculation of the formation energy, the spontaneous magnetization $M_{s}$, the maximum energy product $(B H)_{\max }$, local magnetic moments, the anisotropy constant $K_{1}$, the anisotropy field $H_{a}$, among other useful magnetic quantities. The empirical formula $H_{a}=2 K_{1} /\left(\mu_{0} M\right)$ is used to convert $K_{1}$ values to anisotropy-field values $H_{a}$. An upper bound for the maximum energy product $(B H)_{\max }$, which is a prominent figure of merit for a hard magnet, is estimated according to the empirical formula $(B H)_{\max }^{E S T}=\left(0.9 \mu_{0} M_{s}\right)^{2} /\left(4 \mu_{0}\right)$, which implies the common assumption that at most about $10 \%$ of the volume of a processed bulk permanent magnet consists of non-magnetic phases [15].

The TB-LMTO-ASA calculations were performed using the local spin-density approximation (LSDA), the scalar-relativistic approximation of Koelling and Harmon [23] and the exchange-correlation functional of von Barth and Hedin [24] in the parametrization of Moruzzi et al. [25]. For the k-point sampling of the Brillouin-zone integrals, the linear tetrahedron method and $6 \times 6 \times 4$ Monkhorst-Pack meshes were used. In the ASA the supercell volume is subdivided into spheres and, like in our previous work $[13,14,21]$, we rely on the well-tested ratio for the atomic-sphere radii $r(\mathrm{RE}) / r(\mathrm{TM}) / r(\mathrm{X})=1.35 / 1 / 0.7$ [26].

\subsection{Calculation of the Magnetocrystalline Anisotropy Energy}

We briefly summarize the approach used in this work for the calculation of the magnetrocrystalline anisotropy energy since, aside from the magnetization, this is the key quantity for permanent magnets (for more details see Refs. $[13,20,27,28]$ ). For uniaxial crystal symmetry the MAE is given in first order by

$$
E_{A}=K_{1} \sin ^{2}(\theta)
$$

$K_{1}$ is the first-order anisotropy constant and has the energy-density unit $\mathrm{J} / \mathrm{m}^{3} . \theta$ is the angle of the magnetization vector relative to the easy axis of the crystal. Negative $K_{1}$ values imply an easy plane whereas positive $K_{1}$ values indicate an easy axis. Hard-magnetic materials have positive $K_{1}$ values of the order of $\mathrm{MJ} / \mathrm{m}^{3}$.

For RE-TM compounds the MAE is dominated by the RE contribution [20]. Therefore, $K_{1}$ can be estimated in good approximation by means of the single-ion anisotropy model $[20,27,28]$. In lowest-order approximation $K_{1}$ is proportional to the crystal field parameter $A_{20}$ :

$$
K_{1}=-3 J(J-1 / 2) \alpha_{J}\left\langle r_{4 f}^{2}\right\rangle n_{\mathrm{RE}} A_{20} .
$$

Here, $J$ is the quantum number of the total angular momentum of the $\mathrm{RE}^{3+}$ ion according to Hund's rules and $\alpha_{J}$ is the so-called Stevens factor [29], which accounts for the shape of the charge cloud of the $4 f$ electrons. $\left\langle r_{4 f}^{2}\right\rangle$ is the expectation value of the squared radius of the $4 f$ orbitals at the RE site. The parameters depending on the crystal are $\mathrm{n}_{\mathrm{RE}}$, which is the number of RE atoms per unit cell, and $A_{20}$, which contains the interaction of the RE charge density $\rho_{4 f}(r)$ with the charge density of all the other electrons.

In the single-ion anisotropy model for RE elements, a $4 f$ configuration of a trivalent RE ion is assumed. This is well justified for all RE elements except $\mathrm{Ce}$ and Eu. In our previous work [13], we have assessed the results of the approach by comparison to the experimental values of $K_{1}$ and $H_{a}$ of some long-known and well-studied hard-magnetic materials, and we have proposed heuristic adjustment factors for interpreting the theoretical results: in order to convert our zero-temperature single-domain DFT-HTS results to room temperature estimates the theoretically obtained values for $K_{1}$ and $H_{a}$ are divided by 4 for Nd or Sm containing RE-TM-X phases. Hence, theoretical predicted values of $K_{1}^{A S A} \geq 20 \mathrm{MJ} / \mathrm{m}^{3}$ for 
$\mathrm{Nd}$ or Sm containing compounds correspond to experimental target values of $K_{1} \geq 5 \mathrm{MJ} / \mathrm{m}^{3}$ for very good permanent magnets like $\mathrm{Nd}_{2} \mathrm{Fe}_{14} \mathrm{~B}$. For a comparison of theoretically predicted and experimentally measured $K_{1}$ values for a variety of benchmark compounds see Table 2 in Ref. [13].

\subsection{Phase Stability}

The focus of the screening approach presented in this paper is on the determination of intermetallic phases with promising magnetic key properties. A full assessment regarding the question of phase stability is beyond the scope of this work. Within density functional theory it is a tremendous task to evaluate a complete finite temperature phase diagram taking into account all eventually possible ternary and quaternary phases. And even the knowledge of such an equilibrium phase diagram is insufficient for a final judgment as various out-of-equilibrium fabrication methods can be used to synthesize a metastable phase. As an example, Cadieu et al. [30] succeeded in synthesizing binary $\mathrm{SmFe}_{12}$ films of the $\mathrm{ThMn}_{12}$ structure by rf-sputtering. So far, bulk $\mathrm{REFe}_{12}$ phase could only be obtained by partially replacing Fe with a stabilizing third element, such as Ti, V, or Mo (see, e.g., Refs. [31,32] and references therein).

Another famous recent example of such innovative experimental approaches is the successful synthesis of $\mathrm{NdFe}_{12}$ and $\mathrm{NdFe}_{12} \mathrm{~N}_{x}$ by Hirayama et al. [15]. First principles calculations predicted that $\mathrm{NdFe}_{12} \mathrm{~N}$ has a substantially larger magnetization than $\mathrm{NdFe}_{11} \mathrm{TiN}$ accompanied by a comparable anisotropy field [16]. In order to experimentally validate the theoretical prediction Hirayama et al. successfully synthesized the $\mathrm{NdFe}$ phase by nitriding a $\mathrm{NdFe}_{12}$ thin film that was grown on a tungsten underlayer on a single-crystalline $\mathrm{MgO}(001)$ substrate. A similar synthesis route was later taken by Sato et al. using a vanadium underlayer on $\mathrm{MgO}$ (001) [33]. The authors of Ref. [15] report that the $\mathrm{NdFe}_{12} \mathrm{~N}$ phase was shown to be stable with a thickness of up to $360 \mathrm{~nm}$. This indicates that there may be a possibility to prepare bulk $\mathrm{NdFe}_{12} \mathrm{~N}$ without the need of partially replacing Fe with ternary structure stabilizing elements. However, the challenge of obtaining bulk phases remains to be solved.

In order to be compatible with the original idea of a high-throughput screening, i.e., a systematic search using efficient approaches, we assess the stability of the proposed intermetallic phases by calculating their formation energy $\Delta \epsilon_{f}$ with respect to the elemental constituents at $T=0 \mathrm{~K}$, which is an approximate indicator of the phase stability. For values of $\Delta \epsilon_{f}$ below approximately $0.1 \mathrm{eV}$ the respective phase may be stable. Here, $\pm 0.1 \mathrm{eV} /$ atom is about the accuracy of the TB-LMTO-ASA method for the calculation of formation energies.

\subsection{Structure Models}

The crystal structure of $\mathrm{LaCo}_{9} \mathrm{Si}_{4}$ belongs to the tetragonal space group No. 140 (I4/mcm). For the 1-13 unit cell we have taken the lattice parameters $a=7.833 \AA$ and $c=11.5657 \AA$ and the internal parameters determined experimentally by Michor et al. [12] (see Table 1). Additional interstitial atoms $X=B, C$, or $N$ were inserted at the Wyckoff positions (4c). Since the analysis is focused on hard-magnetic applications with high magnetization a large number of Fe atoms in the unit cell is needed for the most promising compounds. Therefore, in order to have a realistic structure model for the screening, the $\mathrm{LaCo}_{9} \mathrm{Si}_{4}$-type structure was relaxed using the DFT code VASP [34,35] (see Section 2.5 for the numerical settings) with Nd on the (4a) sites and Fe on all the TM sites (4d), (16k), and (161). This structure is denoted 1-13.

In the same way, the lattice parameters $a$ and $c$, as well as the internal coordinates, were relaxed for $\mathrm{NdFe}_{13} \mathrm{~N}$ and a new energy-minimum structure was obtained, which is denoted 1-13-X (see Figure 1). The unit cells of the 1-13 and 1-13-X structures contain 56 and 60 atoms, respectively. 
Table 1. Experimental internal structural parameters of $\mathrm{LaCo}_{9} \mathrm{Si}_{4}$ taken from Michor et al. [12] are compared to the structural parameters of $\mathrm{NdFe}_{13}$ and $\mathrm{NdFe}_{13} \mathrm{~N}$, which were obtained by density functional theory (DFT) optimization of the lattice parameters $a$ and $c$ as well as all the internal coordinates. Wyckoff positions (4a) and (4d) are equal for all structures and given by $(0,0,1 / 4)$ and $(0,1 / 2,0)$, respectively. The interstitial $\mathrm{N}$ atoms in $\mathrm{NdFe}_{13} \mathrm{~N}$ are located at Wyckoff positions (4c) represented by $(0,0,1 / 2)$.

\begin{tabular}{|c|c|c|c|c|c|c|c|c|c|}
\hline \multirow{2}{*}{$\begin{array}{l}\text { Wyckoff Position } \\
\text { Representative Site }\end{array}$} & \multicolumn{3}{|c|}{ (16k) } & \multicolumn{3}{|c|}{ (161) } & \multicolumn{3}{|c|}{ (161) } \\
\hline & $x$ & $\mathbf{y}$ & $\mathbf{z}$ & $x$ & $\mathbf{y}$ & $\mathbf{z}$ & $x$ & $\mathbf{y}$ & $\mathbf{z}$ \\
\hline $\mathrm{LaCo}_{9} \mathrm{Si}_{4}$ & 0.070 & 0.201 & 0 & 0.627 & 0.127 & 0.180 & 0.170 & 0.670 & 0.121 \\
\hline $\mathrm{NdFe}_{13}$ & 0.064 & 0.203 & 0 & 0.617 & 0.117 & 0.180 & 0.180 & 0.680 & 0.117 \\
\hline $\mathrm{NdFe}_{13} \mathrm{~N}$ & 0.067 & 0.211 & 0 & 0.615 & 0.115 & 0.180 & 0.179 & 0.679 & 0.116 \\
\hline
\end{tabular}
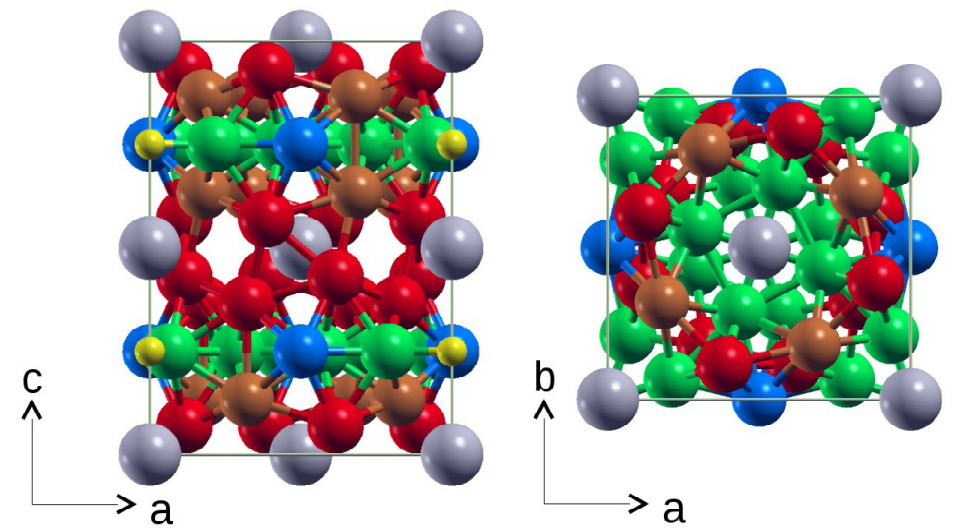

Figure 1. (Color online) Structure model of the $\mathrm{NdFe}_{13} \mathrm{X}(1-13-\mathrm{X})$ phases. Large grey spheres represent $\mathrm{Nd}$ atoms and small yellow spheres represent interstitial atoms $\mathrm{X}=\mathrm{B}, \mathrm{C}$, or $\mathrm{N}$. The Fe atoms are shown as spheres of medium size in red, blue, brown, and green, corresponding to the four Wyckoff positions. The structure model of $\mathrm{NdFe}_{13}$ (1-13) looks very similar due to the little deviations in lattice and internal parameters but of course the (4c) Wyckoff positions remain unoccupied.

As in our previous work [13,14] we keep the structural parameters of the densely packed 1-13-X structure type constant while substituting different RE, TM, and interstitial elements. The $\mathrm{NdFe}_{13} \mathrm{~N}$ structure was also taken for the HTS of phases containing B or C since test calculations with the optimized lattice and internal parameters of $\mathrm{NdFe}_{13} \mathrm{~B}$ and $\mathrm{NdFe}_{13} \mathrm{C}$ showed only deviations on the order of $1 \%$ of the magnetic quantities relative to the results obtained for $\mathrm{NdFe}_{13} \mathrm{~N}$. For a quantitative study of the effects of individual structural relaxations for each compound we refer to our study of the 1-11 phase in Ref. [14].

\subsection{Structural Relaxation with VASP}

The relaxations of the 1-13 and 1-13-X models were carried out using the projector-augmented-wave (PAW) method [36], as implemented in the VASP code [34,35]. Exchange-correlation is taken into account in the generalized gradient approximation (GGA) [37]. For Nd we have taken the PAW potential named "Nd_3", which keeps the $4 f$ electrons frozen in the core. The number of $4 f$ electrons in the core equals the number of valence electrons minus 3, which is the formal valence [38]. For Fe the PAW potential "Fe_pv" was used, which treats the $3 p$ electrons as valence electrons. Finally, for $\mathrm{N}$ we have taken the provided potential with 5 valence electrons. The VASP calculations were carried out with a plane-wave cutoff energy of $520 \mathrm{eV}$, a $3 \times 3 \times 2$ Monkhorst-Pack [39] k-mesh, and a Gaussian broadening of $0.05 \mathrm{eV}$.

Note that for the relaxation of the structural parameters a treatment of the $4 \mathrm{f}$-electrons which are strongly localized close to the atomic core as 'open-core' states (like it is done within TB-LMTO-ASA) is of 
minor importance. This justifies the use of the reliable and efficient PAW pseudopotential approach and the GGA for this task.

\section{Results and Discussion}

\subsection{Crystal Structures}

The calculated lattice parameters of the DFT-relaxed $\mathrm{NdFe}_{13}(1-13)$ structure are $a=8.129 \AA$ and $c=11.503 \AA$. The optimized internal parameters are rounded to three digits and given in Table 1 . Placing the larger Fe atoms on the lattice sites of the smaller $\mathrm{Si}$ atoms leads to some internal rearrangement and an increase of the lattice parameter $a$. The slight decrease of $c$ with respect to $\mathrm{LaCo}_{9} \mathrm{Si}_{4}$ can be attributed mainly to the substitution of La by the smaller $\mathrm{Nd}$ atoms. An aspect ratio $c / a \approx \sqrt{2}$ is obtained which means that for Fe instead of $\mathrm{Co}$ and $\mathrm{Si}$ (in the ratio 9:4) on the TM sites the relaxed 1-13 structure loses the tetragonality of the $\mathrm{LaCo}_{9} \mathrm{Si}_{4}$ structure yielding the cubic $\mathrm{NaZn}_{13}$ structure with modified lattice parameters. The $\mathrm{NdFe}_{13}$ structure is not used for the screening, only its X-ray diffraction pattern is calculated for comparison to that of $\mathrm{NdFe}_{13} \mathrm{~N}$ (see Appendix A).

The lattice parameters of the $\mathrm{NdFe}_{13} \mathrm{~N}(1-13-\mathrm{X})$ structure resulting from the DFT relaxation are $a=8.357 \AA$ and $c=11.393 \AA$. The $c / a$ ratio of the lattice parameters of the relaxed 1-13-X structure is $c / a \approx 1.3633 \approx 0.965 \sqrt{2}$. The interstitial $\mathrm{N}$ provokes a shrinking of the $c$ axis compared to the cubic $1-13$ phase, and this mainly affects the Wyckoff positions (161). The Fe atoms on (161) swerve in the $x$ - and $\mathrm{y}$-directions. This designed 1-13-X phase serves as a template structure for the screening. Its $c / a$ ratio is similar to the tetragonal one of $\mathrm{LaCo}_{9} \mathrm{Si}_{4} c / a=11.5657 / 7.833 \approx 1.044 \sqrt{2}$ determined experimentally by Michor et al. [12].

The calculated X-ray diffraction patterns of $\mathrm{NdFe}_{13}$ and $\mathrm{NdFe}_{13} \mathrm{~N}$ are provided in Appendix A. The rather small differences in the internal coordinates lead to significant differences in the peak positions and their ordering at least for some diffraction angles $2 \theta$. Most pronounced is the distinction for the 215, 323, and 411 peaks, which almost coincide for $\mathrm{NdFe}_{13}$ but split for $\mathrm{NdFe}_{13} \mathrm{~N}$ and appear in the reversed sequence 411, 323, and 215 (see Figure 2 and Table A1). Moreover, the strong 312 peak shifts about one degree downwards from $\mathrm{NdFe}_{13}$ to $\mathrm{NdFe}_{13} \mathrm{~N}$.

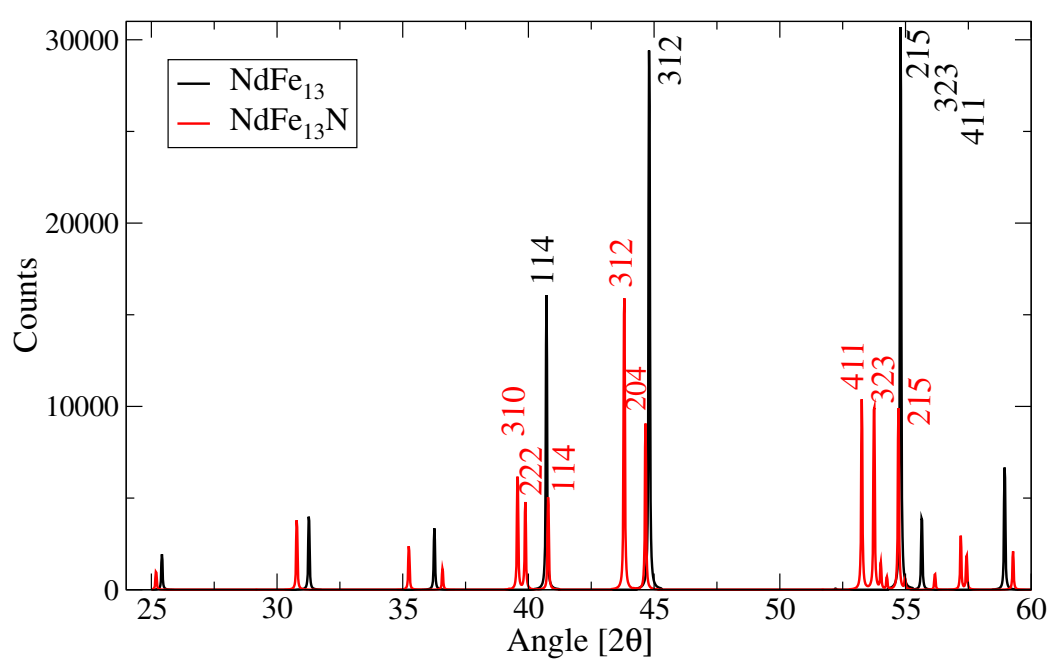

Figure 2. (Color online) Comparison of the diffraction patterns of $\mathrm{NdFe}_{13}$ und $\mathrm{NdFe}_{13} \mathrm{~N}$ calculated for a cobalt cathode with PowderCell 2.4 [40]. The peaks 215, 323, and 411 of $\mathrm{NdFe}_{13}$ lie on top of the 215 peak of $\mathrm{NdFe}_{13} \mathrm{~N}$. The angles and amplitudes can be found in Table A1. 


\subsection{Results of the Screening}

Table 2 gives a small selection of the HTS results of altogether 1250 compounds of 1-13-X structures with their calculated magnetic properties, which fulfill the selection criteria $(B H)_{\max }^{E S T} \geq 400 \mathrm{~kJ} / \mathrm{m}^{3}$ and $K_{1}^{A S A} \geq 20 \mathrm{MJ} / \mathrm{m}^{3}$ for potentially good hard-magnetic phases. All the listed phases have negative formation energies $\Delta \epsilon_{f}$ with respect to the elemental bulk phases of their constituents. The magnitude of $-\Delta \epsilon_{f}$ is an approximate indicator for the phase stability. Nevertheless, as discussed in Section 2.3, the existence of more competing stable binary or ternary compounds cannot be excluded by this analysis. It is expected that most of the proposed compounds are actually metastable and require special experimental non-equilibrium techniques for their synthesis.

Table 2. Selection of screening results. Key quantities calculated with tight-binding linear-muffin-tin-orbital atomic-sphere approximation (TB-LMTO-ASA) are listed: the maximum energy product $(B H)_{\max }^{E S T}$, the spontaneous magnetization $M_{S}^{A S A}$, the anisotropy constant $\mathrm{K}_{1}^{A S A}$, and the anisotropy field $H_{a}^{A S A}$. The last column lists the formation energies $\Delta \epsilon_{f}$ at $T=0 \mathrm{~K}$ with respect to the elemental constituents (cf. discussion in Section 2.3). For comparison, the table includes the theoretical results for $\mathrm{Nd}_{2} \mathrm{Fe}_{14} \mathrm{~B}$ and $\mathrm{SmCo}_{5}$ as the two benchmark compounds with the highest experimental values for maximum energy product $(B H)_{\max }$ and anisotropy field $H_{a}$. Furthermore, $\mathrm{Sm}_{2} \mathrm{Fe}_{17} \mathrm{~N}_{3}$ is given, which consists of $\mathrm{Sm}$, Fe, and $\mathrm{N}$ just like $\mathrm{SmFe}_{13} \mathrm{~N}$, the screening result with the highest value of $(B H){ }_{\max }^{E S T}$. Experimental data taken from ${ }^{a}$ Ref. [41], ${ }^{b}$ Ref. [42], and ${ }^{c}$ Ref. [43] (Table 11.1 therein) are given in brackets. The experimental $M_{s}$ values are determined at $4 \mathrm{~K}$, whereas $K_{1}$ and $H_{a}$ are room-temperature values. The most promising candidates for new hard-magnetic phases obtained from the HTS are highlighted in bold letters. Our selection criteria are $(B H)_{\max }^{E S T} \geq 400$ $\mathrm{kJ} / \mathrm{m}^{3}$ and $K_{1}^{A S A} \geq 20 \mathrm{MJ} / \mathrm{m}^{3}$, as well as $\Delta \epsilon_{f}<0.1 \mathrm{eV} /$ atom.

\begin{tabular}{|c|c|c|c|c|c|}
\hline System & $\begin{array}{c}(\mathrm{BH})_{\max }^{E S T} \\
\left(\mathrm{~kJ} / \mathrm{m}^{3}\right)\end{array}$ & $\begin{array}{c}\mu_{0} \mathbf{M}_{s}^{A S A} \\
(\mathrm{~T})\end{array}$ & $\begin{array}{c}\mathrm{K}_{1}^{A S A} \\
\left(\mathrm{MJ} / \mathrm{m}^{3}\right)\end{array}$ & $\begin{array}{c}\mu_{0} \mathbf{H}_{a}^{A S A} \\
\text { (T) }\end{array}$ & $\begin{array}{c}\Delta \epsilon_{f} \\
\text { (eV/atom) }\end{array}$ \\
\hline $\mathrm{NdFe}_{13} \mathrm{~B}$ & 617 & 1.96 & 0 & 0 & -0.25 \\
\hline $\mathrm{NdFe}_{13} \mathrm{C}$ & 611 & 1.95 & -10 & -16 & -0.20 \\
\hline $\mathrm{NdFe}_{13} \mathrm{~N}$ & 660 & 2.02 & -19 & -23 & -0.44 \\
\hline $\mathrm{NdCo}_{13} \mathrm{~N}$ & 327 & 1.42 & -13 & -29 & -0.34 \\
\hline $\mathrm{SmFe}_{13} \mathrm{~B}$ & 526 & 1.81 & 2 & 3 & -0.26 \\
\hline $\mathrm{SmFe}_{13} \mathrm{C}$ & 521 & 1.80 & 19 & 26 & -0.22 \\
\hline $\mathbf{S m F e}_{13} \mathbf{N}$ & 566 & 1.87 & 34 & 45 & -0.45 \\
\hline $\mathrm{SmCo}_{13} \mathrm{~N}$ & 262 & 1.27 & 24 & 48 & -0.35 \\
\hline $\mathrm{SmFe}_{12} \mathrm{TiN}$ & 406 & 1.59 & 34 & 54 & -0.54 \\
\hline $\mathrm{SmFe}_{12} \mathbf{V N}$ & 411 & 1.60 & 36 & 57 & -0.52 \\
\hline $\mathrm{SmFe}_{12} \mathrm{CoN}$ & 551 & 1.85 & 33 & 45 & -0.44 \\
\hline $\mathrm{SmFe}_{12} \mathrm{NiN}$ & 506 & 1.77 & 34 & 48 & -0.43 \\
\hline $\mathrm{SmFe}_{12} \mathrm{CuN}$ & 481 & 1.73 & 33 & 48 & -0.41 \\
\hline $\mathrm{SmFe}_{12} \mathrm{ZnN}$ & 459 & 1.68 & 34 & 50 & -0.46 \\
\hline $\mathrm{SmFe}_{12} \mathrm{GaN}$ & 434 & 1.64 & 34 & 53 & -0.56 \\
\hline $\mathrm{SmFe}_{12} \mathrm{AlN}$ & 418 & 1.61 & 36 & 56 & -0.56 \\
\hline $\mathrm{SmFe}_{12} \mathrm{SiN}$ & 410 & 1.59 & 36 & 57 & -0.63 \\
\hline $\mathrm{SmFe}_{12} \mathrm{PN}$ & 423 & 1.62 & 37 & 57 & -0.65 \\
\hline $\mathrm{Nd}_{2} \mathrm{Fe}_{14} \mathrm{~B}$ & $556\left(516^{a}\right)$ & $1.87\left(1.86^{b}\right)$ & $19\left(4.9^{c}\right)$ & $26\left(6.7^{c}\right)$ & -0.02 \\
\hline $\mathrm{SmCO}_{5}$ & $174\left(219^{a}\right)$ & $1.04\left(1.07^{c}\right)$ & $69\left(17.2^{c}\right)$ & $162\left(40.4^{c}\right)$ & 0.06 \\
\hline $\mathrm{Sm}_{2} \mathrm{Fe}_{17} \mathrm{~N}_{3}$ & $459\left(472^{a}\right)$ & $1.69\left(1.54^{c}\right)$ & $27\left(8.6^{c}\right)$ & $40\left(14.0^{c}\right)$ & -0.82 \\
\hline
\end{tabular}


Regarding the magnetocrystalline anisotropy, the $\mathrm{NdTM}_{13} \mathrm{X}$ compounds with $\mathrm{X}=\mathrm{B}, \mathrm{C}$, or $\mathrm{N}$ mainly have $K_{1}$ values which are negative or close to zero. There is a trend for the $\mathrm{Nd}$-containing 1-13-X phases that $K_{1}$ decreases from $B$ via $C$ to $N$ (see Table 2). For $\operatorname{SmTM}_{13} X$ the trend is oppositely showing an increase when going from $\mathrm{B}$ via $\mathrm{C}$ to $\mathrm{N}$ and the $K_{1}$ values are all positive. The difference in sign is well understood from the shapes of the $4 f$ charge clouds which are oblate for $\mathrm{Nd}$ but prolate for Sm [43].

Comparing $\mathrm{SmCo}_{13} \mathrm{~N}$ and $\mathrm{SmFe}_{13} \mathrm{~N}$ (or $\mathrm{NdCo}_{13} \mathrm{~N}$ and $\mathrm{NdFe}_{13} \mathrm{~N}$ ), one can see that an improvement of the magnetization and $(B H){ }_{\max }^{E S T}$ can be achieved by substituting $\mathrm{Co}$ with $\mathrm{Fe} . \mathrm{SmFe}_{13} \mathrm{C}$ and $\mathrm{SmFe}_{13} \mathrm{~N}$ have values for $(B H)_{\max }^{E S T}$ which are as high as that of $\mathrm{Nd}_{2} \mathrm{Fe}_{14}$ B. For $S m \mathrm{Fe}_{13} \mathrm{~N}$, even higher $K_{1}$ and $\mathrm{H}_{a}$ values are predicted. Converting the calculated anisotropy field of 45 Tesla (at $0 \mathrm{~K}$ ) for $\mathrm{SmFe}{ }_{13} \mathrm{~N}$ by the division of 4 (the heuristic adjustment factor for $\mathrm{Sm}$ and $\mathrm{Nd}$ ) leads to about 11 Tesla at room temperature. This field is close to the experimentally measured value of 8.6 Tesla of $\mathrm{Sm}_{2} \mathrm{Fe}_{17} \mathrm{~N}_{3}$ (see Table 2). According to our calculation, one may expect a higher magnetization for $S m \mathrm{Fe}_{13} \mathrm{~N}$ than for $\mathrm{Sm}_{2} \mathrm{Fe}_{17} \mathrm{~N}_{3}$.

Since $\mathrm{SmFe}_{13} \mathrm{~N}$ is a highly promising compound, and in order to make sure that taking the relaxed structure of $\mathrm{NdFe}_{13} \mathrm{~N}$ as input geometry does not lead to significant errors, we have a posteriori also relaxed the $\mathrm{SmFe}_{13} \mathrm{~N}$ structure using VASP. The obtained lattice parameters are $a=8.343 \AA$ and $c=11.374 \AA$. These values as well as all the internal coordinates deviate only marginally from the ones obtained for $\mathrm{NdFe}_{13} \mathrm{~N}$. The magnetization evaluated with TB-LMTO-ASA for the fully relaxed structure is $\mathrm{M}_{s}=1.84 \mathrm{~T}$ and the anisotropy constant is $K_{1}=36 \mathrm{MJ} / \mathrm{m}^{3}$. Altogether, $\mathrm{M}$ changes by about $1 \%$ and $K_{1}$ by about $5 \%$ compared to the values obtained from the HTS. This again illustrates that the screening approach with fixed structural parameters works well for the studied densely packed crystal structure and that it allows a reliable identification of phases with good hard-magnetic key quantities. This justifies that setting the focus on fast and efficient screening rather than on high precision is reasonable.

A partial substitution of $\mathrm{Fe}$ by $\mathrm{Co}$ or $\mathrm{Ni}$ also leads to promising compounds like $\mathrm{SmFe}_{12} \mathrm{CoN}$ and $\mathrm{SmFe}_{12} \mathrm{NiN}$. The decrease in magnetization may be compensated by a higher phase stability as might be expected from the experience in the synthesis of the 1-12 phase [32]. Furthermore, an increase of the Co content like in $\mathrm{SmFe}_{12} \mathrm{CoN}$ may increase the Curie temperature. We cannot quantify this effect by our present calculations but refer to the common observation in intermetallic phases that Co leads to higher Curie temperatures than Fe [1].

The substitution of $\mathrm{Fe}$ atoms by non-magnetic elements $\mathrm{A}=\mathrm{Cu}, \mathrm{Zn}, \mathrm{Ga}, \mathrm{Sn}, \mathrm{Ti}, \mathrm{V}, \mathrm{Al}, \mathrm{Si}$, or P leads to a decrease of the magnetization accompanied with an increase of the anisotropy constant $K_{1}$ in most cases. Going, e.g., from $\mathrm{SmFe}_{13} \mathrm{~N}$ to $\mathrm{SmFe}_{12} \mathrm{Ti}_{1} \mathrm{~N}$ and to $\mathrm{SmFe}_{9} \mathrm{Ti}_{4} \mathrm{~N}$, the magnetization $\mathrm{M}$ decreases from $1.87 \mathrm{~T}$ to $1.59 \mathrm{~T}$ and to $0.56 \mathrm{~T}$ and $K_{1}$ changes from 34 and 34 to $47 \mathrm{MJ} / \mathrm{m}^{3}$. As already mentioned in the introduction, only small amounts of non-magnetic elements may be introduced for phase stabilization, otherwise the magnetization breaks down drastically. The increasing stability is reflected by the calculated negative formation energies $\left(\Delta \epsilon_{f}\right)$ relative to the elemental phases. The formation energy per atom decreases from $-0.45 \mathrm{eV}$ to $-0.54 \mathrm{eV}$ and to $-0.71 \mathrm{eV}$ going from $S m \mathrm{Se}_{13} \mathrm{~N}$ to $S m \mathrm{Fe}_{12} \mathrm{Ti}_{1} \mathrm{~N}$ and to $\mathrm{SmFe}_{9} \mathrm{Ti}_{4} \mathrm{~N}$.

For the non-magnetic elements $\mathrm{A}=\mathrm{Cu}, \mathrm{Zn}, \mathrm{Ti}, \mathrm{Al}, \mathrm{Si}$, or $\mathrm{P}$, the compounds $\mathrm{SmFe}_{12} \mathrm{AN}$ have an estimated maximum energy product of more than $400 \mathrm{~kJ} / \mathrm{m}^{3}$ combined with large $K_{1}$ values. This makes them potentially interesting and promising hard-magnetic compounds. The calculated values in Table 2 are given for elements A on the Wyckoff position (4d). In another study it was shown that there is only a minor dependence of the hard-magnetic properties on the sites of the alloying elements A [44]. 


\subsection{Comparison to $\mathrm{ThM} n_{12}$ Compounds}

The local crystal fields in the immediate neighborhood of the RE atoms in RE intermetallic phases determine the sign of $K_{1}$. In the literature the local situations in $\operatorname{Sm}\left(\mathrm{Fe}_{11} \mathrm{Ti}\right), \mathrm{Sm}\left(\mathrm{Fe}_{11} \mathrm{Ti}\right) \mathrm{N}_{1-\delta}$, and $\mathrm{Sm}_{2} \mathrm{Fe}_{17} \mathrm{~N}_{3-\theta}$ are discussed $[45,46]$. In the 1-13-X structure, the interstitials form dumbbells in the c-direction with the RE atoms like in the $\mathrm{ThMn}_{12}$ (1-12-X) crystal structure (see, e.g., the sketch in Figure 13 of Ref. [45]). Thus, at first glance one would expect the same sign of $K_{1}$ for the two structures, depending only on the prolate or oblate charge cloud of the RE atoms. But the situation for $\mathrm{Nd}$ and $\mathrm{Sm}$ in the $1-13-X$ crystal structure is opposite to that of the 1-12-X crystal structure. The results are summarized in Table 3. We performed cross-check calculations by applying the c/a ratio of the 1-12-X crystal to the 1-13-X crystal while keeping the volume fixed. The results obtained in this way are an easy axis for $\mathrm{NdFe}_{13} \mathrm{~N}\left(K_{1}=42 \mathrm{MJ} / \mathrm{m}^{3}\right)$ and an easy plane for $\operatorname{SmFe}{ }_{13} \mathrm{~N}\left(K_{1}=-63 \mathrm{MJ} / \mathrm{m}^{3}\right)$. Applying the $\mathrm{c} /$ a ratio of the 1-13-X crystal to the 1-12-X crystal with fixed volume reverses the sign of $K_{1}$ as well. $\mathrm{NdFe}_{12} \mathrm{~N}$ has no longer an easy axis $\left(K_{1}=-26 \mathrm{MJ} / \mathrm{m}^{3}\right)$ but now $\operatorname{SmFe}_{12} \mathrm{~N}$ has one $\left(K_{1}=49 \mathrm{MJ} / \mathrm{m}^{3}\right)$. As commonly known, in the 1-12-X structure $\mathrm{Nd}$ leads to an easy axis in the c-direction whereas Sm leads to an easy plane. In order to find out the structural origin for the opposite magnetic behavior of the two types of intermetallic compounds, we analyzed in detail the local distances and angles between the RE atoms and their neighboring Fe and $\mathrm{N}$ atoms. Our finding is that it is not due to the differently shaped Fe polyhedra around the RE atoms, but the significant difference is the distance of the interstitial $\mathrm{N}$ atoms to the RE atoms. In the $1-12-X$ crystal structure the interstitials are at a distance of $\sim 2.40 \AA$. In the 1-13-X crystal structure they are situated much further at $\sim 2.84 \AA$. Displacing two neighboring interstitials artificially from $2.40 \AA$ to $2.84 \AA$ away from a particular RE site in $R_{E F e}{ }_{12} \mathrm{~N}$, or vice versa from $2.84 \AA$ to $2.40 \AA$ towards a RE site in $\mathrm{REFe}_{13} \mathrm{~N}$, causes the value of the local crystal-field parameter $\mathrm{A}_{20}$ at this RE site to change its sign and, hence, the local anisotropy changes direction. By the change of the c/a ratio, all distances between RE and interstitial atoms are changed and consequently, according to Equation (2), $K_{1}$ changes sign because the signs of the $A_{20}$ at all RE sites are changed in the same manner.

Table 3. Anisotropy constant $K_{1}$ for a selection of compounds where the $c / a$ ratio was either the one of $\mathrm{ThMn}_{12}(1-12-\mathrm{X})$ or 1-13-X. * For comparison of 1-12-X and 1-13-X only half of the unit cell of the 1-13-X crystal structure in the c-direction, as shown in Figure 1, is considered. The corresponding $c / a$ value of 0.682 is one half of $c / a=11.393 \AA / 8.357 \AA$.

\begin{tabular}{lcccc}
\hline$K_{\mathbf{1}}\left(\mathbf{M J} / \mathbf{m}^{\mathbf{3}}\right)$ & $\mathbf{N d F e}_{\mathbf{1 2}} \mathbf{N}$ & $\mathbf{N d F e}_{\mathbf{1 3}} \mathbf{N}$ & $\mathbf{S m F e}_{\mathbf{1 2}} \mathbf{N}$ & $\mathbf{S m F e}_{\mathbf{1 3}} \mathbf{N}$ \\
\hline$c / a=0.561(1-12-\mathrm{X})$ & $\mathbf{4 7}$ & 42 & $-\mathbf{7 1}$ & -63 \\
$c / a=0.682^{*}(1-13-\mathrm{X})$ & -26 & $-\mathbf{1 9}$ & 49 & 34 \\
\hline
\end{tabular}

\section{Summary}

By means of electronic-structure calculations, we have screened the magnetic properties of 1250 different RE-TM-X compounds with 1-13-X structure as potential candidates for new hard-magnetic phases. A novel tetragonal 1-13-X structure was constructed from the $\mathrm{LaCo}_{9} \mathrm{Si}_{4}$ structure by decoration with interstitial elements on (4c) sites and subsequent structural relaxation.

The TB-LMTO-ASA method determines the single-crystal magnetization $M_{s}$ with good accuracy, which allows an estimation of the maximum energy product $(\mathrm{BH})_{\max }$. It also provides a qualitative theoretical estimate for the first-order magnetocrystalline anisotropy constant $K_{1}$ and anisotropy field $H_{a}$, based on the single-ion anisotropy model for RE elements. 
With this approach, no promising RE-TM-X phases with 1-13-X structures containing Nd were found. This is opposite to the case of the $1-12-\mathrm{X}\left(\mathrm{ThMn}_{12}\right)$ crystal structure, where the introduction of dumbells formed from the interstitial atoms leads to an easy axis symmetry. However, in the 1-13-X crystal structure the interstitials are approximately $0.44 \AA$ more distant from the RE atoms than in the $\mathrm{ThMn}_{12}$ crystal structure. We found that this is the origin that the 1-13-X structure provides a suitable local environment with easy-axis anisotropy for prolate Sm atoms.

Thus, the HTS led to several promising Sm-containing phases, namely $\mathrm{SmFe}_{13} \mathrm{~N}$ and $\mathrm{SmFe}_{12} \mathrm{AN}$, with $\mathrm{A}=\mathrm{Co}, \mathrm{Ni}, \mathrm{Cu}, \mathrm{Zn}, \mathrm{Ga}, \mathrm{Ti}, \mathrm{V}, \mathrm{Al}, \mathrm{Si}$, or $\mathrm{P}$. These compounds have a maximum energy product $(\mathrm{BH})_{\max }$ higher than $400 \mathrm{~kJ} / \mathrm{m}^{3}$, combined with sufficiently large $K_{1}$ and $H_{a}$ values necessary for permanent-magnet applications. $\mathrm{SmFe}_{13} \mathrm{~N}$ may even have the potential to compete with $\mathrm{Nd}_{2} \mathrm{Fe}_{14} \mathrm{~B}$. We hope that this may foster experimental efforts to synthesize such promising hard-magnetic compounds.

Author Contributions: Conceptualization, C.E. and O.G.; methodology, C.E.; software, G.K.; validation, G.K., W.K. and D.F.U.; formal analysis, G.K., W.K. and D.F.U.; investigation, G.K., W.K. and D.F.U.; data curation, G.K. and W.K.; writing-original draft preparation, G.K. and W.K.; writing-review and editing, D.F.U., C.E. and O.G.; visualization, W.K. and D.F.U.; supervision, C.E.; funding acquisition, C.E. and O.G.

Funding: Financial support for this work was provided by the Fraunhofer Lighthouse Project Critical Rare Earths and partially financed within the LOEWE project RESPONSE funded by the Ministry of Higher Education, Research and the Arts (HMWK) of Hessen.

Acknowledgments: The authors thank A. Buckow and J. Gassmann for valuable discussions.

Conflicts of Interest: The authors declare no conflict of interest.

\section{Appendix A}

The addition of interstitial nitrogen to the 1-13 structure $\mathrm{NdFe}_{13}$ leads to some significant changes in the simulated X-ray diffraction pattern. These changes can be best seen for small diffraction angles between 25 and 60 degrees. Figure 2 shows the calculated patterns of the considered $\mathrm{NdFe}_{13}$ und $\mathrm{NdFe}_{13} \mathrm{~N}$ single crystals whose structures were relaxed by DFT calculations using VASP (see Section 2.5). A short discussion can be found in Section 3.1. 
Table A1. Diffraction-peak positions and intensities for the crystal structures of $\mathrm{NdFe}_{13}$ and $\mathrm{NdFe}_{13} \mathrm{~N}$ calculated with the software PowderCell (version 2.4) [40] for a cobalt cathode. As X-ray source a Co cathode was assumed $\left(K \alpha_{1}=1.789007 \mathrm{~nm}\right)$. Only the range for $2 \Theta$ from 25 to 60 degrees is listed. The intensities are given in \% relative to the strongest peak 312 . This peak and the three peaks 215,323 , and 411 , which are addressed in Section 3.1, are marked by bold digits.

\begin{tabular}{|c|c|c|c|c|c|c|c|c|c|}
\hline \multicolumn{6}{|c|}{$\mathrm{NdFe}_{13}$} & \multicolumn{4}{|c|}{$\mathrm{NdFe}_{13} \mathrm{~N}$} \\
\hline $\mathbf{H}$ & $\mathbf{K}$ & L & $2 \Theta$ & I/rel. & $\mathbf{H}$ & $\mathbf{K}$ & L & $2 \Theta$ & I/rel. \\
\hline 1 & 1 & 2 & 25.421 & 6.56 & 2 & 0 & 0 & 24.722 & 6.36 \\
\hline 2 & 0 & 0 & 25.424 & 3.20 & 1 & 1 & 2 & 25.188 & 6.14 \\
\hline 2 & 1 & 1 & 29.906 & 0.00 & 2 & 1 & 1 & 29.177 & 0.07 \\
\hline 2 & 0 & 2 & 31.267 & 20.62 & 2 & 0 & 2 & 30.785 & 23.46 \\
\hline 0 & 0 & 4 & 36.255 & 5.65 & 2 & 2 & 0 & 35.245 & 14.70 \\
\hline 2 & 2 & 0 & 36.263 & 11.29 & 0 & 0 & 4 & 36.584 & 7.05 \\
\hline 2 & 1 & 3 & 39.642 & 0.00 & 2 & 1 & 3 & 39.230 & 0.14 \\
\hline 1 & 1 & 4 & 40.714 & 27.01 & 3 & 1 & 0 & 39.568 & 38.96 \\
\hline 2 & 2 & 2 & 40.720 & 27.13 & 2 & 2 & 2 & 39.876 & 29.24 \\
\hline 3 & 1 & 0 & 40.721 & 27.06 & 1 & 1 & 4 & 40.786 & 31.35 \\
\hline 2 & 0 & 4 & 44.802 & 50.24 & 3 & 1 & 2 & 43.812 & 100.00 \\
\hline 3 & 1 & 2 & 44.807 & 100.00 & 2 & 0 & 4 & 44.657 & 55.56 \\
\hline 3 & 2 & 1 & 47.689 & 0.00 & 3 & 2 & 1 & 46.385 & 0.01 \\
\hline 2 & 2 & 4 & 52.215 & 0.23 & 4 & 0 & 0 & 50.700 & 0.01 \\
\hline 4 & 0 & 0 & 52.221 & 0.09 & 2 & 2 & 4 & 51.708 & 0.08 \\
\hline 2 & 1 & 5 & 54.800 & 52.35 & 4 & 1 & 1 & 53.262 & 63.36 \\
\hline 3 & 2 & 3 & 54.806 & 52.28 & 3 & 2 & 3 & 53.751 & 63.47 \\
\hline 4 & 1 & 1 & 54.808 & 52.34 & 3 & 3 & 0 & 54.016 & 8.71 \\
\hline 0 & 0 & 6 & 55.640 & 4.63 & 4 & 0 & 2 & 54.259 & 4.10 \\
\hline 3 & 1 & 4 & 55.647 & 4.42 & 2 & 1 & 5 & 54.719 & 60.42 \\
\hline 4 & 0 & 2 & 55.652 & 2.27 & 3 & 1 & 4 & 54.981 & 3.35 \\
\hline 3 & 3 & 0 & 55.653 & 9.36 & 0 & 0 & 6 & 56.171 & 5.37 \\
\hline 1 & 1 & 6 & 58.938 & 11.56 & 4 & 2 & 0 & 57.199 & 17.86 \\
\hline 3 & 3 & 2 & 58.949 & 11.63 & 3 & 3 & 2 & 57.432 & 11.60 \\
\hline 4 & 2 & 0 & 58.950 & 11.49 & 1 & 1 & 6 & 59.277 & 12.83 \\
\hline
\end{tabular}

\section{References}

1. Coey, J.M.D. Hard Magnetic Materials: A Perspective. IEEE. Trans. Magn. 2011, 47, 4671-4681. [CrossRef]

2. Gutfleisch, O.; Willard, M.A.; Brück, E.; Chen, C.H.; Sankar, S.G.; Liu, J.P. Magnetic materials and devices for the 21st century: Stronger, lighter, and more energy efficient. Adv. Mater. 2011, 23, 821-842. [CrossRef]

3. Kuz'min, M.D.; Skokov, K.P.; Jian, H.; Radulov, I.; Gutfleisch, O. Towards high-performance permanent magnets without rare earths. J. Phys. Condens. Matter 2014, 26, 064205.

4. Felser, C.; Wollmann, L.; Chadov, S.; Fecher, G.H.; Parkin, S.S.P. Basics and prospective of magnetic Heusler compounds. Appl. Mater. 2015, 3, 041518. [CrossRef]

5. Fujieda, S.; Fujita, A.; Fukamichi, K. Large magnetocaloric effect in $\mathrm{La}_{(}\left(\mathrm{Fe}_{x} \mathrm{Si}_{1-x}\right)_{13}$ itinerant-electron metamagnetic compounds. Appl. Phys. Lett. 2002, 81, 1276. [CrossRef]

6. Löwe, K.; Liu, J.; Skokov, K.; Moore, J.D.; Sepehri-Amin, H.; Hono, K.; Katter, M.; Gutfleisch, O. The effect of the thermal decomposition reaction on the mechanical and magnetocaloric properties of $\mathrm{La}(\mathrm{Fe}, \mathrm{Si}, \mathrm{Co})_{13}$. Acta Mater. 2012, 60, 4268-4276. [CrossRef]

7. Skokov, K.P.; Karpenkov, A.Y.; Karpenkov, D.Y.; Gutfleisch, O. Heat exchangers made of polymer-bonded $\mathrm{La}(\mathrm{Fe}, \mathrm{Si})_{13}$. J. Appl. Phys. 2014, 115, 17A941. [CrossRef] 
8. Skokov, K.P.; Müller, K.-H.; Moore, J.D.; Liu, J.; Karpenkov, A.Y.; Krautz, M.; Gutfleisch, O. Influence of thermal hysteresis and field cycling on the magnetocaloric effect in $\mathrm{LaFe}_{11.6} \mathrm{Si}_{1.4}$. J. Alloys Compd. 2013, 552, $310-317$. [CrossRef]

9. Krautz, M.; Skokov, K.; Gottschall, T.; Teixeira, C.S.; Waske, A.; Liu, J.; Schultz, L.; Gutfleisch, O. Systematic investigation of $\mathrm{Mn}$ substituted $\mathrm{La}(\mathrm{Fe}, \mathrm{Si})_{13}$ alloys and their hydrides for room-temperature magnetocaloric application. J. Alloys Compd. 2014, 598, 27-32. [CrossRef]

10. Shen, Y.; Turgut, Z.; Horwath, J.; Yang, M. Bulk nanocomposite $\mathrm{LaCo}_{5} / \mathrm{LaCo}_{13}$ magnets J. Appl. Phys. 2011, 109, 07A765. [CrossRef]

11. Pani, M.; Manfrinetti, P.; Provino, A.; Yuan, F.; Mozharivskyj, Y.; Morozkin, A.V.; Knotko, A.V.; Garshev, A.V.; Yapaskurt, V.O.; Isnard, O. New tetragonal derivatives of cubic NaZn 13 -type structures: $\mathrm{RNi}_{6} \mathrm{Si}_{6}$ compounds, crystal structure and magnetic ordering (R=Y,La,Ce,Sm,Gd-Yb). J. Solid State Chem. 2014, 210, 45-52. [CrossRef]

12. Michor, H.; El-Hagary, M.; Mea, M.D.; Pieper, M.W.; Reissner, M.; Hilscher, G.; Khmelevskyi, S.; Mohn, P.; Schneider, G.; Giester, G.; et al. Itinerant electron metamagnetism in LaCogSi 4 . Phys. Rev. B 2004, 69, 081404. [CrossRef]

13. Körner, W.; Krugel, G.; Elsässer, C. Theoretical screening of intermetallic $\mathrm{ThMn}_{12}$-type phases for new hard-magnetic compounds with low rare earth content. Sci. Rep. 2016, 6, 24686.

14. Körner, W.; Krugel, G.; Urban, D.F.; Elsässer, C. Screening of rare-earth-lean intermetallic 1-11 and 1-11-X compounds of $\mathrm{YNi}_{9} \mathrm{In}_{2}$-type for hard-magnetic applications. Scr. Mater. 2018, 154, 295.

15. Hirayama, Y.; Takahashi, Y.K.; Hirosawa, S.; Hono, K. $\mathrm{NdFe}_{12} \mathrm{~N}_{x}$ hard-magnetic compound with high magnetization and anisotropy field. Scr. Mater. 2015, 95, 70-72. [CrossRef]

16. Miyake, T.; Terakura, K.; Harashima, Y.; Kino, H.; Ishibashi, S. First-Principles Study of Magnetocrystalline Anisotropy and Magnetization in $\mathrm{NdFe}_{12}, \mathrm{NdFe}_{11} \mathrm{Ti}$, and $\mathrm{NdFe}_{11} \mathrm{TiN}$. J. Phys. Soc. Jpn. 2014, 83, 043702. [CrossRef]

17. Harashima, Y.; Terakura, K.; Kino, H.; Ishibashi, S.; Miyake, T. First-Principles Study of Structural and Magnetic Properties of $\mathrm{R}(\mathrm{Fe}, \mathrm{Ti})_{12}$ and $\mathrm{R}(\mathrm{Fe}, \mathrm{Ti})_{12} \mathrm{~N}(\mathrm{R}=\mathrm{Nd}, \mathrm{Sm}, \mathrm{Y})$. JPS Conf. Proc. 2015, 5, 011021.

18. Andersen, O.K. Linear methods in band theory. Phys. Rev. B 1975, 12, 3060. [CrossRef]

19. Hummler, K.; Fähnle, M. Ab initio calculation of local magnetic moments and the crystal field in $\mathrm{scrR}_{2} \mathrm{Fe}_{14} \mathrm{~B}$ (scrR = Gd, Tb, Dy, Ho, and Er). Phys. Rev. B 1992, 45, 3161. [CrossRef]

20. Fähnle, M.; Hummler, K.; Liebs, M.; Beuerle, T. Ab initio electron theory for hard-magnetic rare-earthtransition-metal intermetallics. Appl. Phys. A 1993, 57, 67-76. [CrossRef]

21. Drebov, N.; Martinez-Limia, A.; Kunz, L.; Gola, A.; Shigematsu, T.; Eckl, T.; Gumbsch, P.; Elsässer, C. Ab initio screening methodology applied to the search for new permanent magnetic materials. New J. Phys. 2013, 15, 125023. [CrossRef]

22. Brooks, M.S.S.; Nordström, L.; Johannson, B. 3d-5d band magnetism in rare earth-transition metal intermetallics: Total and partial magnetic moments of the $\mathrm{RFe}_{2}(\mathrm{R}=\mathrm{Gd}-\mathrm{Yb})$ Laves phase compounds. J. Phys. Condens. Matter 1991, 3, 2357. [CrossRef]

23. Koelling, D.D.; Harmon, B.N. A technique for relativistic spin-polarised calculations. J. Phys. C Solid State Phys. 1977, 10, 3107. [CrossRef]

24. Von Barth, U.; Hedin, L. A local exchange-correlation potential for the spin polarized case. J. Phys. C Solid State Phys. 1972, 5, 1629.

25. Moruzzi, V.L.; Janak, J.F.; Williams, A.R. Calculated Electronic Properties of Metals; Pergamon: New York, NY, USA, 1978.

26. Beuerle, T.; Fähnle, M. Ab initio calculation of magnetic moments and hyperfine fields in $Y_{2} \mathrm{Fe}_{17} Z_{3}(Z=H, C, N)$. Phys. Stat. Solidi B 1992, 174, 257-272. [CrossRef]

27. Richter, M.; Oppeneer, P.M.; Eschrig, H.; Johansson, B. Calculated crystal-field parameters of SmCo5. Phys. Rev. B 1992, 46, 13919. [CrossRef]

28. Richter, M. Band structure theory of magnetism in 3d-4f compounds. J. Phys. D Appl. Phys. 1998, 31, 1017-1048. [CrossRef] 
29. Stevens, K.W.H. Matrix Elements and Operator Equivalents Connected with the Magnetic Properties of Rare Earth Ions. Proc. Phys. Soc. 1952, A65, 209-215. [CrossRef]

30. Cadieu, F.J.; Hegde, H.; Navarathna, A.; Rani, R.; Chen, K. High-energy product ThMn12 Sm-Fe-T and Sm-Fe permanent magnets synthesized as oriented sputtered films. Appl. Phys. Lett. 1991, 59, 875. [CrossRef]

31. Ohashi, K.; Yokoyama, T.; Osugi, R.; Tawara, Y. The magnetic and structural properties of R-Ti-Fe Ternary compounds. IEEE Trans. Magn. 1987, 23, 3101-3103. [CrossRef]

32. Akayama, M.; Fujii, H.; Yamamoto, K.; Tatami, K. Physical properties of nitrogenated RFe 11 Ti intermetallic compounds ( $\mathrm{R}=\mathrm{Ce}$, Pr and Nd) with ThMn 12 -type structure. J. Magn. Magn. Mater. 1994, 130, 99. [CrossRef]

33. Sato, T.; Ohsuna, T.; Yano, M.; Kato, A.; Kaneko, Y. Permanent magnetic properties of $\mathrm{NdFe}_{12} \mathrm{~N}_{x}$ sputtered films epitaxially grown on V buffer layer. J. Appl. Phys. 2017, 122, 053903. [CrossRef]

34. Kresse, G.; Furthmüller, J. Efficient iterative schemes for ab initio total-energy calculations using a plane-wave basis set. Phys. Rev. B 1996, 54, 11169. [CrossRef] [PubMed]

35. Kresse, G.; Joubert, D. From ultrasoft pseudopotentials to the projector augmented-wave method. Phys. Rev. B 1999, 59, 1758. [CrossRef]

36. Blöchl, P.E. Projector augmented-wave method. Phys. Rev. B 1994, 50, 17953.

37. Perdew, J.P.; Burke, K.; Ernzerhof, M. Generalized Gradient Approximation Made Simple. Phys. Rev. Lett. 1996, 77, 3865-3868. [CrossRef]

38. For Details on PAW Potentials Provided with VASP. Available online: http://cms.mpi.univie.ac.at/vasp/vasp/ PAW_potentials.html (accessed on 9 August 2019).

39. Monkhorst, H.J.; Pack, J.D. Special points for Brillouin-zone integrations. Phys. Rev. B 1976, 13, 5188. [CrossRef]

40. Kraus, W.; Nolze, G. POWDER CELL-A program for the representation and manipulation of crystal structures and calculation of the resulting X-ray powder patterns. J. Appl. Cryst. 1996, 29, 301-303. [CrossRef]

41. Buschow, K.H.J. Chapter Rare Earth Magnets: Materials (Table I). In Concise Encyclopedia of Magnetic and Superconducting Materials, 2nd ed.; Elsevier: Amsterdam, The Netherlands, 2005.

42. Herbst, J.F. $\mathrm{R}_{2} \mathrm{Fe}_{14}$ B materials: Intrinsic properties and technological aspects. Rev. Mod. Phys. 1991, 63, 819-898. [CrossRef]

43. Coey, J.M.D. Magnetism and Magnetic Materials; Cambridge University Press: Cambridge, UK, 2010.

44. Butcher, T.; Körner, W.; Krugel, G.; Elsässer, C. Dependence of magnetisation and magnetocrystalline anisotropy on site distribution of alloying elements in RE-TM phases with ThMn $\mathrm{T}_{12}$ structure. J. Magn. Magn. Mater. 2017, 441, 1-5. [CrossRef]

45. Coey, J.M.D. Novel Permanent Magnetic Materials. Phys. Scr. 1991, 39, 21. [CrossRef]

46. Skomski, R.; Kuz'min, M.D.; Coey, J.M.D. Crystal field in nitrogenated rare-earth intermetallics. J. Appl. Phys. 1993, 73, 6934-6936. [CrossRef]

(C) 2019 by the authors. Licensee MDPI, Basel, Switzerland. This article is an open access article distributed under the terms and conditions of the Creative Commons Attribution (CC BY) license (http:/ / creativecommons.org/licenses/by/4.0/). 